\title{
A formação inicial dos professores de Letras
}

\section{LÚCIa de FÁtima Santos}

Profa. da Faculdade de Letras da Universidade

Federal de Alagoas. E-mail: Ifsmar@hotmail.com.

Resumo: Neste texto temos como finalidade refletir sobre a formação inicial dos professores de Letras, a partir de uma discussão dos objetivos defendidos pela universidade $\mathrm{e}$ pelos alunos nessa formação. Para isso, analisamos documentos como as Diretrizes Curriculares Nacionais de Letras (DCNs) e o Exame Nacional de Desempenho (ENADE), que representam a proposta defendida pela universidade, como também os posicionamentos assumidos por um grupo de formandos desse curso em entrevistas realizadas durante a graduaçāo.

Palavras-chave: formação de professor; curso de Letras; universidade; alunos
Résumé: Le contexte de cette étude nous permet de réfléchir sur la formation formation initiale des étudiants -futurs professeurs de la Licence ès Lettres à partir d'une discussion sur les objectifs établis par I'Université et para les étudiants faisant partie de cette formation-là. Pour y aboutir, nous avons analysé des documents tels que les Définitions Curriculaires Nationales du Cursus de Lettres - DCN) et L'Examen National de Performance (Exame Nacional de Desempenho-ENADE), qui représentent les propos de l'Université, ainsi les idées défendues par un groupe d'étudiants de la dernière année de formation à l'Université.

Mots-clés: formation de professeur; Licence ès Lettres; université ; étudiants 

A formação inicial dos professores de Português Língua Materna (doravante PLM) consiste em uma questão pouco discutida nos cursos de licenciatura em Letras, embora constitua objeto de estudo de umas das linhas de pesquisa em expansão na área de Linguística Aplicada (LA) ${ }^{1}$. Reflexões como a de Soares (2000) evidenciam que essa discussão não é recente e exige um redirecionamento urgente. Porém, de um modo geral, observamos que a ênfase principal nesse curso restringe-se à exposição e avaliação de conteúdos sem uma correlação com as orientações pedagógicas dos futuros professores, também sem quaisquer referências às práticas de ensino da educação básica, local onde esses professores atuarão. Talvez uma das razões que justifiquem essa realidade dos cursos de Letras seja a crença de que as questões vinculadas ao ensino são exclusivamente objeto de investigação dos pesquisadores e professores da área de Educação. ${ }^{2}$

O interesse pela formação dos professores de PLM culminou em um dos pontos de reflexão de nossa pesquisa de doutorado ${ }^{3}$. Pelo fato de o enfoque principal dessa pesquisa ter sido a produção de alunos de Letras, inevitavelmente a formação desses alunos como professores esteve em foco em todas as etapas de desenvolvimento do trabalho. Neste artigo retomamos o objetivo de problematizar um pouco a formação dos professores de PLM a partir dos seguintes itens: a proposta defendida pela universidade para a formação inicial dos futuros professores de PLM; os objetivos dos alunos em sua constituição como professores de PLM; a correlação entre o que a universidade propõe e os alunos desejam enquanto futuros professores de PLM. Para isso, adotamos como representações da proposta defendida pela universidade as Diretrizes Curriculares Nacionais de Letras (DCN) e a última prova do Exame Nacional de Desempenho (ENADE). Os objetivos dos alunos foram analisados de acordo com os posicionamentos assumidos por um grupo de quatro graduandos em Letras $^{4}$ da Universidade Federal de Alagoas em diferentes entrevistas durante a graduação.
1 O número crescente de trabalhos apresentados no Intercâmbio de Pesquisas em Linguística Aplicada (INPLA) é uma demonstração do interesse de pesquisadores de LA pelo tema. No último INPLA, realizado em 2007, a formação de professores foi discutida em seis simpósios.

2 No Diretório de Grupos de Pesquisa do $\mathrm{CNPq}$ há 654 registros de grupos de pesquisa sobre formaçâo de professores: 496 são da área de Educação, 36 da área de Linguística (projetos desenvolvidos predominantemente por pesquisadores com formação em LA) e $15 \mathrm{na}$ área de Letras. Informaçōes obtidas em http://www. cnpq.br, em 30 de janeiro de 2008.

3 A tese tem como titulo Produção de textos na universidade: em busca de atitudes ativas e táticas (2007),e foi defendida no Programa de PósGraduação em Letras e Lingüistica da UFAL, sob a orientação da Profa. Dra. Rita Zozzoli. Este artigo é parte das reflexões desenvolvidas na tese.

4 Esses alunos foram sujeitos da pesquisa que desenvolvemos no decorrer de dois anos letivos. 


\section{A proposta da universidade para a formação dos alunos de Letras}

Em análises realizadas sobre a produção de alunos de Letras, pesquisadores como Barian (1978), Pécora (1992), Conceição (2002) e Santos (2007) apresentam sérias dificuldades desses alunos como produtores de textos. De uma forma categórica, Pécora (1992, p.4) afirma:

De repente, no interior de uma universidade de primeiro nível no âmbito da educação brasileira, questionava-se se os seus alunos possuíam um suporte primário do processo de alfabetização. De repente, e para o espanto de todos, inclusive dos próprios alunos. Naquele momento, após

${ }^{5}$ Sistema escriturístico é a expressão usada por De Certeau (2002, p.261) para criticar as estratégias usadas na tentativa de "moldar o público pelo escrito (verbal ou icônico)", tornando-o semelhante ao que recebe. Desse modo, o público passa a repetir o que lhe é imposto nos textos. cumprirem, talvez sofrivelmente, massem maiores embaraços, um período de aproximadamente quatro anos na universidade, parecia inexplicável que não dispusessem de elementos que lhes permitissem interpretar adequadamente um texto conhecido e escrever umas poucas linhas a seu respeito.

Ao apresentar essa caracterização dos alunos, esse pesquisador explicita, ainda que indiretamente, o trabalho que é desenvolvido na rotina das salas de aula de ensino de PLM na universidade e coloca em evidência aspectos da formação inicial desses alunos que, sob um outro enfoque, foram reiterados por Conceição (2002) e Santos (2007). Com a denúncia sobre a impossibilidade de os alunos realizarem os projetos de escrita que a universidade elabora a partir das prescrições dos sistemas escriturísticos $^{5}$ (DE CERTEAU, 2002), são denunciadas e questionadas também, de certo modo, as orientações teórico-metodológicas adotadas no curso de Letras. Se os alunos cursam quatro anos da graduação e não dispõem de elementos que lhes permitam "interpretar adequadamente um texto conhecido e escrever umas poucas linhas a seu respeito," que trabalho está sendo ou deve ser desenvolvido para reverter essa situação? Até 
onde alcança o poder de interferência dos professores na (re)orientação dessa condição dos alunos como produtores de textos? O que, efetivamente, a universidade propõe para a formação desses alunos como professores de língua materna?

Levando-se em consideração que as determinações das DCNs de Letras ${ }^{6}$ representam os objetivos da formação de professores de línguas nas universidade, ${ }^{7}$ podemos afirmar que a proposta de formação de professores defendida pela universidade não corresponde "à caracterização de um professor que se deseja para mudar o quadro do ensino de línguas" (SANTOS, 2005, p.95). Santos se opõe ao perfil idealizado do graduado em Letras que é definido nesse documento como um conjunto de múltiplas competências e habilidades que o aluno adquire durante sua formação acadêmica convencional, teórica e prática, ou fora dela. Nesse perfil enfatizam-se as características individuais do futuro profissional de Letras numa perspectiva subjetivista e cognitivista. De acordo com essa autora, as dificuldades da formação dos alunos em Letras não se resolvem com propostas desvinculadas da realidade de cada curso, nem "com o engessamento de habilidades e competências," como propõem as DCN e, consequentemente, a universidade.

Esse modo de conceber a formação do futuro professor de Letras integra-se a uma visão de ensino na qual a linguagem é vista como expressão do pensamento. Orientar a formação dos professores sob essa visão significa corresponder às ideias das determinações dos produtores do conhecimento (MEC, ENADE, universidades, entre outros). Com base em De Certeau (2002, p. 262), o discurso de eficácia das DCNs propicia a inércia, assegurando, assim, a produção da ideologia do consumo-receptáculo. Ainda segundo esse autor, essa ideologia é "necessária ao sistema que distingue e privilegia autores, pedagogos, revolucionários, numa palavra 'produtores' daqueles que não o são." Logo os alunos que não consumirem os produtos de acordo com essas determinações não sabem pensar, por isso não sabem escrever, nem ler, nem falar
- As Diretrizes

Curriculares de Letras foram instituidas através da Resolução CNE/CES 18 , de 13 de março de 2002 , tendo como fundamento - Parecer CNE/CES n ${ }^{\circ}$ 492, de 3 de abril de 2001. Esse Parecer foi retificado pelo Parecer CNE/CES n ${ }^{\circ}$ 1.363, de 12 de dezembro de 2001.

${ }^{7}$ Essa afirmação se fundamenta no Edital n* 4/97 que convocou as Instituiçōes de Educação Superior (IES) a encaminhar propostas para a elaboração das diretrizes curriculares dos cursos de graduação. 
${ }^{8}$ Para preservar a identidade dos alunos, os nomes são fictícios.

${ }^{9}$ O pronome ela tem como referente a professora do primeiro e do quarto ano. e, em se tratando de futuros professores de PLM, não se sentem capazes de assumir esse lugar. Os reflexos dessa lei do consumo são explícitos em diferentes trechos das entrevistas realizadas com os alunos. Alguns alunos sentem-se quase totalmente analfabetos em relação à língua que escrevem, leem e utilizam em diversas relações dialógicas, como é o caso de Bianca8:

O quarto ano é triste. A gente começa a sentir medo. Eu não estou preparada para dar aula de Língua Portuguesa (...) Se eu fosse seguir um modelo, eu seguiria o que ela ${ }^{9}$ fazia, mas para mim é muito difícil fazer isso: pegar um texto e trabalhar da forma que ela trabalhava. Eu não sei se é a minha leitura que é pouca, eu não sei se é o meu conhecimento da língua praticamente zero [...] Eu não gosto no primário de trabalhar nomenclaturas, você dizer isso é um sujeito, isso é um predicado, isso é um substantivo tal, isso é num sei o quê. Pra mim, eles não precisariam trabalhar com tanta nomenclatura, mas a gente não consegue fugir disso. Me angustia às vezes a questão de eu querer trabalhar de uma forma e não conseguir e não poder. [grifo nosso]

Essa insegurança expressa por Bianca no final do curso deve-se, sobretudo, às lacunas presentes em sua formação. Ela explicita isso em uma avaliação que apresenta dos quatro anos de graduação ao criticar, entre outros aspectos, a ausência de atividades de produção de textos durante o curso. Segundo ela, essas atividades apenas aconteceram em duas disciplinas no decorrer da graduação. Além disso, ela reconhece a exigência que the é imposta para tornar-se uma profissional em Letras. De acordo com as Diretrizes:

O objetivo do Curso de Letras é formar profissionais interculturalmente competentes, capazes de lidar, de forma crítica, com as 
linguagens, especialmente a verbal, nos contextos oral e escrito, e conscientes de sua inserção na sociedade e das relações com o outro.

Também, segundo as Diretrizes,

o profissional em Letras deve ter domínio do uso da língua ou das línguas que são objeto de seus estudos, em termos de sua estrutura, funcionamento e manifestações culturais, além de ter consciência das variedades lingüísticas e culturais. Deve ser capaz de refletir teoricamente sobre a linguagem, de fazer uso de novas tecnologias e de compreender sua formação profissional como processo contínuo, autônomo e permanente. A pesquisa e a extensão, além do ensino, devem articular-se neste processo. $O$ profissional deve, ainda, ter capacidade de reflexão crítica sobre temas e questões relativas aos conhecimentos lingüísticos e literários.

O objetivo de uma formação teórica e prática dos professores, tanto inicial quanto continuada, sob uma perspectiva reflexiva, crítica e articulada com a pesquisa é imprescindível para a alteração do quadro de ensino de PLM, porém jamais poderá ser instituído com o caráter de arbitrariedade como foram implantadas as DCNs e, de um modo geral, todos os documentos que orientam as questões educacionais. Nesse sentido, observe-se, por exemplo, a recorrência da forma verbal "dever" nessa citação, contrariando a ideia de flexibilidade defendida como um princípio norteador dessa proposta. Se adotássemos esse objetivo como verdade indiscutível, diríamos que as inadequações presentes nas produções dos alunos justificam-se pela incompetência destes para lidar com a linguagem escrita, bem como pela incapacidade de reflexão crítica sobre temas e questões relativas aos conhecimentos linguísticos. Porém todos os professores comprometidos com o trabalho de formação dos alunos 
${ }^{10}$ De acordo com a tipologia proposta por Marcuschi (2001), essas questōes correspondem meramente a uma atividade de decodificação. de Letras compreendem que, na extensa proposta desse objetivo das DCNs, há estratégias implícitas como interesse de desencadear comportamentos de passividade como aquele expresso por Bianca. Esses profissionais também reconhecem que tal proposta é irreal e inexequível em muitas, senão em todas, universidades brasileiras, por razões como aponta Oliveira (2003, p.66), ao constatar que nos currículos dos cursos de Letras, especificamente as disciplinas relacionadas à questão da língua, "em sua grande maioria, permanecem assentadas em concepções tradicionais de linguagem." Lima (2003) ratifica essa posição ao concluir que professores universitários ainda priorizam a concepção de língua como representação e não como atividade discursiva.

Além das Diretrizes, consideramos o Exame Nacional de Desempenho dos Estudantes (ENADE), que é parte do Sistema Nacional de Avaliação da Educação Superior (SINAES), também com um documento oficial que representa os objetivos da universidade na formação dos futuros professores. Nesse sentido, o artigo quarto da Portaria 175 (24/8/05), que institui o ENADE/2005, determina como objetivos nas letras d e e, respectivamente: "analisar e refletir criticamente acerca dos conteúdos referentes a estudos lingüísticos e literários e à formação profissional" e "abordar criticamente as perspectivas teóricas adotadas nas investigações lingüísticas e literárias." Porém quase toda a constituição da prova com questões objetivas ${ }^{10}$ é contraditória com a proposta de análise, reflexão e criticidade, como se confirma na seguinte questão:

O discurso citado é o discurso no discurso, a enunciação na enunciação, mas é, ao mesmo tempo, um discurso sobre o discurso, uma enunciação sobre a enunciação. (M. Bakhtin. Marxismo e filosofia da linguagem)

Consideradas as afirmações acima, é correto apontar, como marca de discurso de outrem no depoimento do Dr. Lambada, o uso de: 
(A) pronome demonstrativo - como em e aquilo precisa ser bem feito -, por meio do qual um outro contrapõe sua visão depreciativa do trabalho da ONG à visão defendida pelo enunciador.

(B) argumentos de autoridade - como os fornecidos para compor o perfil do Dr. Zapata Lambada - que conferem maior veracidade às impressões pessoais do artista.

(C) discurso direto - como minha mulher diz chega -, em que a citação de um outro enunciado expõe uma divergência para dar veracidade ao depoimento do enunciador.

(D) formas de inclusão - como em Muitas vezes somos...-, que instauram a cumplicidade entre enunciador e enunciatário por meio da inclusão deste último enunciado.

(E) índices de ironia - como em Acredita em doentes saudáveis -, pois o enunciador crítica crenças ultrapassadas dos Doutores da Alegria.

A correlação entre os objetivos mencionados nas letras d e e da Portaria 175 e esse tipo de questão permite-nos afirmar que a proposta de ensino de PLM na universidade não forma professores críticos e reflexivos. Em que aspectos, efetivamente, essa questão avalia uma análise crítica das perspectivas teóricas adotadas nas investigações linguísticas? Como se pretender do aluno uma compreensão responsivo-ativa sobre a perspectiva teórica de Bakhtin em uma avaliação desse tipo? Mencionar Bakhtin, numa situação de monólogo fechada e irreal como essa, constitui um enorme paradoxo. Essa situação ilustra o que dissemos anteriormente sobre as estratégias de comportamentos de passividade implícitos nas determinações das DCNs, estritamente vinculadas aos objetivos dessa prova. Uma proposta de avaliação com questões desse tipo não contribui para a constituição de sujeitos ativos (tal como defende BAKHTIN, 1992), como também é antagônica com o objetivo das DCNs de formar profissionais "capazes de lidar, de forma crítica, com as 
11 Essa determinação está expressa na Lei 10.861 , no artigo quinto, parágrafo décimo. Tal premiação assemelha-se à entrega de medalhas $e$ diploma aos alunos que são considerados exemplos de ótimo rendimento e disciplina: prática ainda frequente em algumas escolas brasileiras.

12 Cf. Portaria 175, artigo $4^{\circ}$, letra $\mathrm{f}$. linguagens, especialmente a verbal, nos contextos oral e escrito, e conscientes de sua inserção na sociedade e das relações com o outro" (p.31). Um dado agravante nessa situação é que os sujeitos avaliados, num futuro muito próximo, orientarão práticas de ensino. Ou seja, serão professores responsáveis pela formação de outros alunos.

Uma questão contundente no ENADE é que os alunos com melhor desempenho nesse exame são premiados com "bolsa de estudos, ou auxílio específico, ou ainda alguma outra forma de distinção com objetivo similar, destinado a favorecer a excelência e a continuidade dos estudos ${ }^{11}$." Com base nas ideias de De Certeau (2004 e 2005), podemos afirmar que são premiados os alunos que respondem mais afirmativamente aos esquemas estratégicos, aqueles que melhor se enquadram nas imposições das habilidades e das competências previstas para a sua formação. São esses os alunos que, de fato, demonstram "compreender a formação profissional como processo contínuo, autônomo e permanente, à luz da dinâmica do mercado de trabalho ${ }^{12}$."

Esse propósito retoma um dos itens das habilidades e competências estabelecidas nas DCNs (p.24): "preparação profissional atualizada, de acordo com a dinâmica do mercado de trabalho". Pressupõe-se então que a obediência aos interesses do mercado foi a principal causa de as orientações para o ensino serem pautadas em habilidades e competências que atendam a esse fim. Isso nos leva a crer que a ênfase exacerbada em habilidades e competências, na proposta da formação de professores de PLM oferecida pela universidade, atende ao objetivo de submeter os alunos "a grades intelectuais que não lhes parecem organizadas nem em função de suas questões nem em função do seu futuro" (DE CERTEAU, 2005, p. 104). Ainda segundo esse autor, esses alunos não percebem mais no ensino que lhes é imposto "seu valor de instrumentalidade cultural e social. Muitas vezes restalhe apenas um muro a transpor, um obstáculo a superar, uma condição imposta, para chegar às profissões que se encontram do outro lado." Nessas circunstâncias, a 
universidade "faz o papel de polícia," cedendo às pressões - "das mais elevadas às mais utilitárias" - de todas as ambições, revelando-se, assim, incapaz de produzir uma cultura de massa, que é constituída pelas atividades dos não produtores oficiais de cultura.

Os aspectos discutidos por De Certeau sobre as universidades francesas se assemelham a vários pontos críticos das universidades brasileiras, seja em relação à pesquisa, ao ensino ou à extensão (tríade sobre a qual se pautam os trabalhos desenvolvidos nestas universidades). Por exemplo, tanto nas universidades francesas quanto nas universidades brasileiras o status atribuído a alguns campos de pesquisa representa uma dificuldade enfrentada por aqueles que não se inserem nesse contexto de poder. Na realidade brasileira, os cursos de Letras (parece-nos que as licenciaturas de um modo geral) são constituídos majoritariamente por alunos que não gozam de privilégios sócioeconômicos e culturais. Isso interfere também na formação dos alunos, porém a universidade parece desconsiderar realidade como essa nas orientações pedagógicas. A ênfase exacerbada em conteúdos sem o reconhecimento das dificuldades que os alunos apresentam para compreendê-los devido às lacunas de sua formação anterior à universidade é um dos pontos básicos que necessita ser repensado no cotidiano desse curso.

De um modo geral, o curso de Letras caracterizase por aulas estritamente teóricas. ${ }^{13}$ Excetuando-se as experiências do estágio, realizadas no último ano do curso, e as atividades esparsas de algumas disciplinas, basicamente inexiste uma preocupação dos professores de vincular as discussões teóricas à prática (e viceversa), conforme declarações dos alunos. Além de quase não acontecer essa integração entre teoria e prática, os alunos não saem do curso distinguindo uma perspectiva teórica da outra, ou seja, ficam perdidos na grande miscelância de teorias, incutida por "partidários" de perspectivas linguísticas e literárias distintas, apresentadas em cada disciplina.
13 Fazemos essa afirmação com base nas declaraçōes dos alunos no decorrer das entrevistas e também levando em consideração a grade curricular do curso durante os anos da graduação desses alunos. A partir de 2005, foi implantada uma nova grade curricular. 
14 Garcia \& Alves (2002) e Lima (2003) ratificam essa possibilidade.

$\mathrm{Na}$ análise sobre a formação teórica do curso de Letras, Oliveira (2001) observou que, nas grades curriculares dos cursos de licenciatura em Letras, apenas $15 \%$ dos conteúdos obrigatórios das disciplinas sobre língua materna contemplam uma abordagem enunciativa e discursiva (havia currículos em que esses conteúdos inexistiam). Ainda, segundo essa autora, os demais conteúdos das disciplinas centram-se em estudos descritivos da língua, predominando as discussões acerca dos modelos linguísticos que estudam a língua sob uma visão estruturalista ou gerativista. Considerando que essas grades curriculares expressam a direção teóricometodológica a ser posta em execução nas salas de aula, encontram-se facilmente muitas das razões por que os alunos apresentam as dificuldades de ler e produzir um texto. Submetidos a uma visão idealizada e abstrata de língua, centrada em análises totalmente desvinculadas dos contextos de uso da linguagem nos espaços dialógicos de que participam em suas relações sociais, os futuros professores, mesmo que rejeitem essa perspectiva normativa e prescritiva (como veremos nas posições assumidas por eles no item 2), talvez reproduzam tal perspectiva no cotidiano de suas salas de aula ${ }^{14}$, como aconteceu nas experiências que vivenciaram com seus professores do ensino fundamental e médio:

Durante o ensino médio e o ensino fundamental eu estudei a gramática isolada do texto. Nós líamos, mas por ler, não havia uma preocupação: vamos verificar porque o autor utilizou essa expressão. Não havia essa preocupação, por exemplo. (Helena)

Em minha vida escolar, no fundamental, mal tive produção textual, e o ensino médio, como eu fiz um curso técnico, também tinha poucas produções textuais, não trabalhei muito não com isso. (Heloísa) 
Eu falo por mim, eu não aprendo português. Agora, pegando os livros de $1^{a}, 2^{a}$, acho que $3^{\mathfrak{a}}$ e $4^{a}$ série e tá lá português, parece que o mesmo português com pouca diferença. Já aquilo no primário e depois no fundamental de $5^{\mathrm{a}}$ a $8^{\mathrm{a}}$ e depois repete de novo no médio. A Língua Portuguesa é um repeteco porque o método ta equivocado. (Gabriel)

Certamente para pesquisadores como Benites (2003), Kleiman (2001), Oliveira (2001a, 2001b, 2003, 2006), Zozzoli (2003, 2006), entre outros que refletem sobre a formação inicial ou continuada dos professores de línguas, o teor dessas falas não contém novidades. No entanto, apesar da insistência declarada por esses pesquisadores sobre a precariedade da formação dos professores, a tradição pautada no ensino normativo e prescritivo da língua continua prevalecendo. Essas declarações ilustram o porquê de o ensino de PLM, predominantemente centrado na transmissão de conteúdos, já perdurar há muitos anos. A formação que é transmitida pelos professores nas universidades é retransmitida aos seus alunos que, tornando-se professores, repassam às gerações seguintes, formando assim um amplo e melancólico círculo de repetição que exprime a sensação de imobilidade e letargia ("parece que o mesmo português"). A pouca diferença que Gabriel percebe talvez se restrinja à mudança de uma série para outra em todos os anos do ensino fundamental e médio. Mesmo na realidade de ensino na universidade, onde os alunos poderiam vivenciar uma aprendizagem, realmente, significativa, já que a orientação do ensino de PLM é responsabilidade de professores e pesquisadores, ainda existe uma grande resistência em relação a mudanças. Desse modo, a formação dos futuros professores difere muito pouco daquela que receberam enquanto alunos do ensino médio e fundamental. Nesse sentido, Gabriel faz a seguinte revelação:

Tem professor que cheguei a ter, professor de Português mesmo aqui na UFAL mermo péssimo, 
ruim, ruim (seqüência pronunciada de forma enfática) professor de escola, pra lá... não era nem pra estar na escola de nível médio, nem fundamental, mas o que a gente, aquele que ensina a regra gramatical, aquela coisinha bem tolinha, trabalhozinho bem tolinho e sem produzir nada, mas bem dentro aqui da universidade. Mas fazer o quê? Não tem melhor.

Ainda que interpretemos essa declaração de Gabriel como um momento de indignação pelo fato de o trabalho desenvolvido por um professor frustrar suas expectativas, tais afirmações corroboram o que temos reafirmado sobre a tendência de os professores reproduzirem as orientações recebidas em sua formação. Em todo caso, não deixa de ser surpreendente que professores que orientam a formação de futuros professores desenvolvam essa prática pedagógica. Esse "trabalhozinho bem tolinho" corresponde a atividades do tipo: preenchimento de lacunas com a flexão da forma verbal entre parênteses, substituição do sujeito simples pelo sujeito composto, escrita de números ordinais por extenso etc. Entre as razões que justificam a permanência de orientações de ensino de línguas como essa, atribuímos um importante papel ao modo como a universidade concebe a formação de professores nessa área.

Mediante as declarações de Oliveira (2003), é possível afirmar que a universidade concebe ensino de PLM como a transmissão de conhecimentos. Sob essa visão, a discussão de temas como leitura, interação em sala de aula, letramento, produção de textos, ensino e aprendizagem de gramática, entre outros já há bastante tempo desenvolvidos pela Linguística Aplicada, quase inexistem nos cursos de Letras (KLEIMAN, 2001). Além disso, uma abordagem discursiva do ensino de PLM, que conduziria a uma concepção de formação de professores de PLM com orientações opostas a essa, ainda não se consolidou, limitando-se apenas a algumas experiências, como a descrita por Zozzoli (2003) e Santos (2007). 
Corrobora também para essa formação lacunar e precária dos professores de PLM o lugar menor de pesquisa que é atribuído a essa questão, principalmente se o pesquisador apresentar seus resultados de pesquisa em uma linguagem acessível. Segundo Zeichner (1998, p. 209), no contexto de pesquisa educacional, "quanto mais abstrato o trabalho, mais alto seu status na hierarquia acadêmica." Essa afirmação esclarece por que as pesquisas que versam sobre temas fechados à compreensão dos pares acadêmicos são vistas, em geral, como de grande contribuição para a comunidade científica, enquanto questões sobre o cotidiano da sala de aula ainda são consideradas temas de menor relevância.

Ainda, de acordo com Zeichner (1998), a produção e utilização de conhecimentos gerados por professores nas escolas não recebem o carimbo de legitimação nem mesmo pelos próprios professores. Povavelmente isso se justifique devido à ausência de pesquisas na formação inicial dos professores, conforme já declararam Cavalcanti \& Moita Lopes (1991). As reflexões sobre as práticas pedagógicas somente são legitimadas quando produzidas por acadêmicos, pela empresa de autores de que fala De Certeau (2004). Porém, na universidade existe resistência dos professores em relação ao estudo de suas próprias práticas (ZEICHNER, 1998). Essa resistência talvez aconteça porque muitas das questões discutidas nas produções científicas desses professores-pesquisadores não correspondam ao trabalho que realizam em sala de aula. Como falam do lugar de "produtores," é muito provável que essas contradições sejam vistas como incompetência diante de seus pares. Talvez por isso existam poucas pesquisas sobre experiências de auto-observação. Nesse sentido, Benites (2003) constatou que havia um distanciamento entre o discurso teórico de professores do ensino fundamental e a metodologia aplicada. É muito provável que essa observação também aconteça com os professores universitários.

Essa concepção defendida pela universidade de fazer pesquisa sobre a sala de aula, e não de dentro da 
15 Essa posição é defendida incisivamente por Zeichner (2002). sala de aula, influencia, de algum modo, a formação dos futuros professores, uma vez que muitas das orientações que recebem estão, provavelmente, fundamentadas em resultados dessas pesquisas. Pelo fato de não concebermos pesquisa em educação sob a perspectiva estritamente acadêmica, questionamos as mudanças propostas para o ensino de PLM, consequentemente, para a formação de professores de PLM, implantadas com base em pesquisas que não analisam dados que partam de dentro da sala de aula. Ao perisarmos sobre mudanças no processo de formação dos professores, julgamos pertinente considerar a posição de De Certeau (2005, p.141-2) de que uma prática significativa "consiste não em receber, mas em exercer a ação pela qual cada um marca aquilo que outros lhe dão para viver e pensar". Transpondo essa reflexão de De Certeau para a cultura de formação de professores de PLM, é preciso considerar que as mudanças das práticas na sala de aula ocorrem paulatinamente e necessitam ter como condição precípua, desde os momentos em que são idealizadas, a participação ativa de todos aqueles que estão envolvidos diretamente com suas causas e consequências, aqueles que serão mais atingidos pelos resultados que possam advir do processo de transformação ${ }^{15}$. No caso da escola, os reflexos imediatos recaem sobre professores e alunos, personagens com os principais papéis nas cenas de ensino e aprendizagem. Por essa razão, não se podem perder de vista, na formação dos futuros professores, as determinações do ensino de línguas no contexto em que atuarão. Em função disso, insistimos na necessidade de quaisquer mudanças sobre ensino considerarem posicionamentos dos professores e alunos na elaboração dessas alterações. Como lembra Zeichner (2002, p. 30):

Até mesmo as reformas que têm sido amplamente identificadas como bem-sucedidas ao influenciar as práticas da sala de aula, tais como a Escola Nova em Colúmbia, falham ao afetar as práticas da sala de aula, depois de ser empacotadas e espalhadas como "coisas" 
para outros professores que não participam do mesmo modo orgânico, como os professores originais, no desenvolvimento da reforma.

Essa posição de Zeichner coaduna-se com a defesa de Zozzoli (2003) em favor das propostas de intervenção. Para ela, qualquer alteração da prática pedagógica pressupõe a aceitação do professor para mudar sua prática e, assim, abrir espaço para o aluno ter direito à autonomia. Nesse sentido, as universidades têm cerceado a autonomia, as possibilidades de expressão de uma atitude ativa e tática dos futuros professores de PLM, determinando que eles consumam pacotes de teorias e práticas seculares, como se observa nas reflexões de Oliveira (2001a e b, 2003) sobre as propostas curriculares de Letras. Também essa autonomia é cerceada quando novas propostas são apresentadas com base em antigas e infrutiferas práticas.

\section{No percurso acadêmico, os objetivos dos alunos}

Iniciaremos a discussão sobre os objetivos dos alunos em sua formação como futuros professores de PLM a partir da justificativa que eles apresentam sobre a opção para cursar Letras, expressa tanto em questionário de caracterização, aplicado no início das aulas do primeiro ano, quanto em alguns momentos das entrevistas. $\mathrm{O}$ posicionamento dos alunos a esse respeito nos permitirá analisar a representação que têm do curso, assim como os interesses implícitos nessa escolha.

Em resposta ao questionário aplicado no início do curso, Bianca, Gabriel e Heloísa ${ }^{16}$ afirmam ter optado pelo curso de Letras porque não conseguiram ser aprovados no vestibular da área em que desejariam atuar: Enfermagem, Odontologia e Direito, respectivamente. Helena é a única que afirma ter escolhido Letras como primeira opção por se identificar com a área. Diante dessas justificativas, pressupomos que Bianca, Gabriel e Heloísa optaram por Letras por ser mais fácil a aprovação no vestibular, ou seja, não precisariam estudar muito para ser professores
16 A fim de preservar a identidade dos alunos, todos os nomes são fictícios. 
de PLM. Além disso, cursando Letras, aprenderiam com mais profundidade a Língua Portuguesa (para eles, a variedade padrão), com a finalidade de atuar em outros campos profissionais. Em entrevista, exceto Gabriel, todas as alunas (Bianca, Heloísa e Helena) retomam a justificativa sobre a opção de ter cursado Letras.

Decidi fazer Letras por essa questão de querer escrever bem, porque a gente vem fazer Letras com essa história de que vai sair escrevendo bem e de querer gostar da Língua Portuguesa e de fazer Espanhol também. (Bianca)

A Língua Portuguesa é a chave pra qualquer profissão, pra tudo, então eu acho que de qualquer forma é um curso importante, pode ajudar até em outras profissões. Eu ainda não estou lecionando, mas ainda não é o que realmente eu quero, mas pelo o que eu já sei até pra estudar pra concurso, pra tudo, eu acho que valeu a pena, porque a Língua Portuguesa é a chave pra tudo, é nosso instrumento pra tudo, valeu muito a pena. (Heloísa)

Essa importância atribuída ao curso de Letras apenas para uma realização de objetivos desvinculados do propósito de buscar a formação como professores de PLM, evidenciada nas falas dessas alunas, também se observa na fala de Helena, única aluna que diz ter afinidade com a área. Ao justificar sua escolha pelo curso de Letras, ela afirma:

Optei por Letras porque sempre me identifiquei com essa área de Letras assim, sempre achei muito bom quando alguém se posiciona sobre um determinado assunto, quando sabe questionar, quando sabe refletir sobre um tema assim político, social, cultural e pra isso precisa ler; e pra ler, pra se dedicar mesmo à leitura ... 
Lógico que em outros cursos todo mundo na vida, todo mundo pode procurar ler de uma maneira autônoma, mas especificamente no curso de Letras você é orientado para isso, você é orientado para ser um bom leitor, aí uma das maneiras de se tornar leitor.

De acordo com as posições assumidas pelos alunos, afirmamos que nenhum dos sujeitos desta pesquisa optou por Letras porque, efetivamente, queria tornar-se professor. A escolha dos alunos por esse curso atende a interesses particulares, concretização de diferentes objetivos, mas não visa à formação como professores. Observamos, principalmente nos posicionamentos de Helena e Heloísa, o desejo de encontrar no curso possibilidades de experiências sobre o que a cultura de elite preconiza acerca do aprendizado da variedade "culta"da língua. Contudo, ainda que os alunos não tenham optado por Letras para garantir uma formação como professores, é sob essa perspectiva que passaremos a analisar os objetivos que almejam em sua formação. Essa posição se justifica por dois motivos: primeiro, a formação profissional oferecida pelo curso de Letras em foco é exclusivamente direcionada à licenciatura; segundo, Bianca, Helena e Heloísa, no final do curso, já atuavam como professoras. E Gabriel, embora na época ainda não assumisse concretamente o lugar de professor, virtualmente ele parecia já falar desse lugar, pois foi um dos alunos que fizeram críticas mais incisivas e também sugestões ao trabalho desenvolvido em PLM. Portanto, de certo modo, todos já enunciavam do lugar de professores de PLM.

Além disso, os interesses que eles expressam para justificar a escolha pelo curso se opõem ao que demonstram conceber sobre ensino de PLM nas posições assumidas em alguns momentos das entrevistas. Nas idéias que defendem, perpassa um encontro tenso entre vozes que se entrecruzam: quando comentam a opção para cursar a graduação em Letras, defendem uma visão de língua como código que devem dominar para se expressar 
"bem" e ter um lugar de status profissional. Contudo, quando falam sobre a realidade do curso, eles parecem enunciar, de fato, do lugar de professores, discutindo e marcando posições sobre o ensino de PLM. Por exemplo, Heloísa, na justificativa sobre a escolha do curso, defende uma concepção de língua mais calcada nas orientações tradicionais de ensino, porém, em resposta a outra questão de uma entrevista, demonstra reconhecer a necessidade de mudanças no ensino de língua, desde que aconteçam de modo estruturado:

Eu acho que o ensino ainda não tá assim perfeito, precisava modernizar, melhorar algumas coisas. Agora também essa proposta de querer modernizar sem dar estrutura também não está funcionando não. A coisa meio que desandou um pouco ultimamente, não melhorou nada. Não era tão bom e também não melhorou nada.

Essa avaliação que Heloísa apresenta sobre o ensino de PLM é motivada principalmente pelas determinações pedagógicas impostas a esse ensino sem uma preocupação com as implicações operacionais causadas por essas determinações. Nesse sentido, os documentos oficiais resultam em propostas basicamente desconsideradas pelos professores em suas práticas pedagógicas, devido, sobretudo, à ausência de uma significação teórica e prática decorrente da não participação deles no processo de discussão e elaboração de tais "orientações." Essa parece ser uma razões por que Heloísa afirma que o propósito de modernização expresso nesses documentos culminam quase sempre em experiências desagradáveis: "a coisa meio que desandou ultimamente, não melhorou nada." Porém, em outro momento da entrevista, Heloísa reconhece momentos em que as inovações resultaram em propostas menos decepcionantes. Ao falar sobre o trabalho desenvolvido sobre ensino de gramática na universidade, ela afirma: 
Elas [as regras gramaticais] são importantes como uma base, mas é necessário outras coisas, elas por si só é um complemento vamos dizer, mas na produção exige outras coisas. Na produção escrita você tem que ter encadeamento de idéias, como por exemplo, coesão textual que é muito importante, que não se vê totalmente em regra gramatical, você tem que ter uma noção. E também escrever é ter o que falar, não é só você ter regras e não ter o que falar, não saber desenvolver seu pensamento. (Heloísa)

Nessa posição, Heloísa dá indícios de um processo de mudança em que parece acreditar, ao conceber que as regras gramaticais ("elas por si só é um complemento") são apenas parte integrante dos recursos necessários na produção de um texto. Portanto, ela demonstra se distanciar de uma visão de escrita que pressupõe exclusivamente a exigência de um conhecimento anterior das regras gramaticais para a produção de um texto. Contudo, Heloísa ainda reconhece um texto como um espaço dialógico, conforme defende Bakhtin (1997). Ela focaliza somente os recursos lingüísticos (como dizer) e o conteúdo (o que dizer) nas condições necessárias à produção de um texto. ${ }^{17}$ Ressaltemos ainda nessa declaração de Heloísa a oscilação entre uma concepção de escrita centrada em uma visão de linguagem como instrumento de comunicação ("escrever é ter o que falar"), cujo foco recai sobre os interesses individuais de dizer do locutor, e uma visão de linguagem como expressão do pensamento ("não saber desenvolver seu pensamento"), que enfatiza a manifestação do pensamento de acordo com a prescrição de normas para falar e escrever "bem".

De acordo com as respostas aos questionamentos sobre produção de textos e ensino de gramática, todos os alunos revelam o objetivo de uma formação distanciada das orientações de ensino ditas tradicionais. Nos diferentes posicionamentos que ele apresentam, verificamos, por um lado, a proposta de distanciamento
17 Vale conferir em Geraldi (1997) essas condiçōes de produção da escrita. 
de uma política de ensino de língua centrada nessas orientações e, de outro lado, a vontade de instauração de mudanças no curso de Letras. Mesmo com dificuldades de relacionar os conhecimentos teóricos à prática de produção (e vice-versa), eles parecem ter convicção das concepções que pretendem adotar em suas práticas pedagógicas, quando criticam aspectos da formação que a universidade lhes propõe. Bianca, por exemplo, faz uma incisiva crítica à proposta curricular de Letras e ao modo como os professores põem em prática essa proposta durante as aulas:

Eu acho quatro anos, não digo perdidos, porque a gente, de certa forma, a gente investe. Mas eu acho que não é que o tempo seja insuficiente, mas as disciplinas são dadas de forma insuficiente. Não há uma integração de Língua Portuguesa do primeiro ano com a do segundo ano, com a do terceiro e a do quarto. Não há uma seqüência, é muito fragmentado. Então eu acho que dessa forma a gente não constrói, por isso que houve esse rompimento com a minha questão de escrita. Se fosse uma coisa mais seqüenciada, eu tenho certeza que no quarto ano pra mim seria mais fácil e não foi. É muito cada um que faça o seu, cada um que planeje o seu curso, não vêem a Língua Portuguesa como um todo. Cada um que faça o seu e dê a aula. Pra mim é insuficiente, muito, muito.

Nessa declaração Bianca denuncia a fragmentação do ensino de PLM desenvolvido durante o curso de graduação, que, segundo Morin (2000), consiste em um dos males da superespecialização do trabalho científico. Ainda nesse posicionamento, Bianca expressa sua negação a uma concepção de ensino de língua como objeto isolado, fragmentado, estático, tal como Bakhtin (1992) refere-se ao objetivismo abstrato. Ao contrário dessa concepção, ela defende um ensino de 
língua como um todo integrado. Sem isso, como ela afirma, professores e alunos não constroem, limitamse apenas ao cumprimento estratégico de exposição de conteúdos isolados. A concepção de ensino de língua que Bianca defende aparece de modo mais explícito nesta declaração:

Eu não gostava da Língua Portuguesa, sabia que precisava muito e não entendia porque eu tinha que usar certas regras e não botava em prática na minha vida. A minha visão de Língua Portuguesa mudou aqui [na universidade]. Foi quando eu comecei associando gramática à construção do texto. Aí facilitou bastante porque a gramática não ficou separada do texto, não ficou separada da fala também.

A aparente contradição entre essa posição de Bianca e a outra imediatamente anterior é desfeita quando se esclarece que aqui ela faz menção apenas às experiências vivenciadas no primeiro e quarto ano, como aconteceu também com os demais alunos. É com base nas experiências de ensino de PLM vivenciadas nesses dois contextos que Helena defende um ensino de gramática interrelacionado com a produção de textos.

Hoje, atualmente, eu procuro escrever sem ... , procurando dar assim os efeitos no texto mediante aquilo que eu estudei sobre a Língua Portuguesa de uma maneira menos tradicional, onde fica muito diferente assim porque dentro do texto a gramática contextualizada, ela tem ... as palavras passam a ter outros valores. Quando ela é dissociada do texto, ela é uma coisa estagnada né, digamos assim.

Essa defesa de um ensino de gramática contextualizado, vinculado a uma concepção de escrita como prática discursiva é confirmada por Helena quando 
fala sobre a importância das atividades de reescrita, inclusive enunciando do lugar de professora:

Muito boa a realização dessa atividade tanto é que hoje, assim, nos meus trabalhos, eu procuro fazer isso com os meus alunos.

Gabriel também enuncia do lugar de futuro professor, ao fazer uma auto-avaliação de seu processo de escrita. Na declaração a seguir, ele reconhece como uma lacuna de sua formação a dificuldade de produzir textos, reiterada em vários momentos das análises de suas produções ("eu me considero acho que regular viu, regular e olhe lá viu. Tenho que melhorar muito ainda.").

Rapaz, eu já tive péssimo, hoje eu me considero acho que regular viu, regular e olhe lá viu. Tenho que melhorar muito ainda. Mesmo hoje eu me formando como professor, mas eu me considero regular, não vou mentir não.

Ainda nessa declaração, Gabriel reconhece a necessidade de um professor de PLM conhecer os aspectos inerentes à produção de um texto. No enunciado: "Mesmo hoje eu me formando como professor, mas eu me considero regular, não vou mentir não," pode-se inferir que os professores de PLM precisam ter domínio sobre os mecanismos de constituição de um texto. Depreende-se também que a dificuldade de produção de textos de Gabriel, assim como de outros formandos, precisa ser discutida na formação dos alunos de Letras, para que os futuros professores se constituam efetivamente como produtores de textos. Essa discussão implica necessariamente alterações em aspectos da organização curricular e nas orientações pedagógicas adotadas pelos professores. Para isso, conforme Zeichner (2002, p.44), é imprescindível que os professores responsáveis pela formação dos alunos compreendam quais interesses políticos são atendidos por suas ações cotidianas. Se as ações empreendidas pelos 
professores na universidade não têm o poder de interferir em todos os problemas da formação desses alunos, elas podem contribuir, ainda que com "minúsculas maneiras de fazer" (DE CERTEAU, 2002), no sentido de construir espaços nos quais se desenvolva um trabalho de formação de PLM que busque corresponder, no limite das possibilidades institucionais, aos objetivos desses alunos.

Assim como Helena, Gabriel objetiva um ensino de PLM em que o estudo de gramática aconteça de modo contextualizado.

Vou logo dizendo que eu não ensino e nem nunca ensinei, só o estágio mesmo, eu nunca ensinei. Agora o que eu acho porque tem a ver com uma parte que eu acho interessante, porque tem que trabalhar com textos, professores dão um cursinho, dão um cursinho muito rapidinho e gostam de trabalhar com frasesinhas prontinhas, aquela coisinha bem ... é a pontuação. Você vê que a pontuação dentro de um texto tem uma importância muito grande e, para você pontuar, você tem que saber análise, você tem que ter um conjunto de conhecimento gramatical pra poder pontuar o texto adequadamente, pontuar dentro do jeito que você quer dar o tom ali daquilo ali, o que é que você quer dizer. Às vezes a pontuação indevida, um lapso de pontuação, você muda totalmente o significado do texto.

Nesse longo pronunciamento de Gabriel, interpretamos a delimitação do seu dizer ("Vou logo dizendo que eu não ensino e nem nunca ensinei, só o estágio mesmo, eu nunca ensinei") como um reconhecimento de que suas reflexões são apenas virtuais, já que não orientou, na condição de professor licenciado, nenhuma atividade de reflexão gramatical como a que defende. Desse modo ele sinaliza para a possibilidade de assumir na prática real da sala de aula outra posição. Do lugar de professor em formação inicial, ele enfatiza a interligação entre os 
recursos lingüísticos ("você tem que saber análise, você tem que ter um conjunto de conhecimento gramatical") e os discursivos ("pontuar dentro do jeito que você quer dar o tom ali daquilo ali, o que é que você quer dizer.") para que se possa "pontuar o texto adequadamente."

Ainda nessa declaração, Gabriel contrapõe-se à orientação descontextualizada do ensino de gramática, expressando, de uma forma irônica, sua rejeição à fragmentação do ensino desenvolvido nessa perspectiva ("professores dão um cursinho dão um cursinho muito rapidinho gostam de trabalhar com frasesinhas prontinhas, aquela coisinha bem ..."). Ressalte-se, nessa oposição declarada ao modo como se ensina gramática, a forma tática e ativa que ele demonstra de apropriação dos conhecimentos lingüístico-discursivos ao usar de modo irônico o diminutivo. Outro aspecto importante que vale mencionar é que Gabriel, assim como as alunas, critica a ausência de reflexões sobre a prática pedagógica, mas não desconsidera a necessidade de uma fundamentação teórica em seu processo de formação, como indica a posição:

Você tem que estudar, né? Tem que estudar muito, pesquisa, ver se aquele conceito é realmente, condiz mermo, se é real (...) às vezes o professor não tem nem preparo e às vezes fica repetindo como papagaio aquilo que vem na gramática, e por aí tem outros equívocos que você tem que pesquisar, estudar, e pesquisar. Aquele que quiser é procurar outros autores, procurar orientações de professores e de colegas mermo e ir à luta.

Além de criticar a formação precária de alguns professores ("às vezes o professor não tem nem preparo," "fica repetindo como papagaio"), ele enfatiza ser indispensável o professor estudar, pesquisar, buscar orientaçãopara ospontos obscurose também os "equívocos" dos temas que precisa desenvolver nas aulas, através da procura em diferentes fontes ("procurar autores, procurar orientações de professores e de colegas"). Nessa afirmação 
infere-se que Gabriel acredita que o professor necessita ter domínio de um tema sob diferentes perspectivas ("ver se aquele conceito é realmente, condiz mermo, se é real"). Porém ele salienta que essa movimentação ativa e tática do professor exige como condição imprescindível a vontade de desenvolver um trabalho que extrapole o cerco da repetição. Par isso ele precisa não consumir passivamente os produtos de ensino (por exemplo, "orientações" das propostas pedagógicas e dos livros didáticos). Porém, segundo Gabriel, assumir essa posição é, realmente, para "aquele que quiser ir à luta". Essa mobilização do professor em busca de uma outra formação é uma exigência para a qual Zozzoli (2003) chama a atenção, enfatizando a importância da atuação do professor em contextos de intervenção.

\section{Universidade e alunos na caminhada acadêmica}

A partir da correlação entre o que a universidade propõe e os objetivos dos alunos para sua formação enquanto professores de PLM, afirmamos que as divergências que se evidenciam entre os propósitos da universidade e dos alunos devem-se a uma série de fatores como a fragmentação da grade curricular; a visão de ensino de línguas centrada na transmissão de conhecimentos abstratos e segmentados; a ausência de práticas pedagógicas articuladas entre os professores; as imposições de propostas curriculares desvinculadas das perspectivas dos alunos, como também a existência de um sistema de avaliação que visa exclusivamente à memorização de conteúdos.

Conforme os posicionamentos dos futuros professores, eles expressam o objetivo de implementação de um ensino de PLM que não se aprisiona a uma grade de habilidades e competências como determinam as Diretrizes Curriculares Nacionais. Todas as declarações apontam para um ensino de PLM em que as questões da língua sejam trabalhadas de modo inter-relacionado com as práticas discursivas. Talvez esse seja o maior 
distanciamento entre o que a universidade propõe e os objetivos que os alunos buscam para sua formação como professores de PLM. Como declara Bianca, as diretrizes adotadas e postas em prática na universidade ainda se distanciam bastante de uma visão plural de ensino e, conseqüentemente, de língua, de cultura, de sujeito, enfim de uma perspectiva que contemple incompletude, intersubjetividade, heterogeneidade, historicidade. $\bigcirc$ enorme fosso que separa a proposta da universidade dos objetivos dos alunos possibilita compreender algumas das dificuldades que eles demonstram na produção de textos e nas reflexões que realizam nos momentos de reescrita. Como já dissemos, os aspectos que eles aprovam para a sua formação ainda se restringem a limitadas experiências vivenciadas em contextos bastante específicos durante toda a graduação.

Diante dessa realidade, há grandes possibilidades de os futuros professores de PLM não atuarem de modo diferente da formação que receberam. Sem dúvida existem professores que não se vinculam às redes de vigilância sociais e jogam com os mecanismos da disciplina (DE CERTEAU, 2002), porém esse grupo ainda é muito pequeno, compõe-se por aqueles que, infringindo as determinações do consumo, buscam maneiras de uso indisciplinares. Nos diferentes posicionamentos que assumem durante as entrevistas, Bianca, Gabriel, Heloísa e Helena expressam querer fazer parte desse grupo. Entretanto, se esses alunos durante todo o curso de Letras basicamente não foram desafiados a escrever e a ler com compreensão, não realizaram atividades de reflexão sobre a gramática da língua, mas apenas repetiram, reproduziram, como é possível esperar que eles orientem, de fato, práticas discursivas de leitura e produção de texto, como também um ensino significativo e produtivo de reflexão gramatical? Ou questionando do lugar do produtor, no caso as Diretrizes Curriculares de Letras, como esperar que, nessa realidade, o futuro professor de línguas apresente um "domínio do uso da língua portuguesa ou de uma língua estrangeira, nas suas 
manifestações oral e escrita, em termos de recepção e produção de textos"? ${ }^{18}$

Zozzoli (1999, p.20), com base em De Certeau (2002), afirma que a transformação dessa realidade não está nas mãos dos professores e alunos enquanto sujeitos, mas se trata de "uma questão social mais ampla que ultrapassa o âmbito da instituição de ensino, perpassa as academias e se instala em várias instâncias no plano social." Isso não quer dizer, porém, que o papel de subversão de cada professor e de cada aluno nas pequenas maneiras de fazer do cotidiano da sala de aula não seja fundamental para reverter essa ordem social e superar a inércia do consumo (DE CERTEAU, 2004). Como lembra Zozzoli (1999, p.20), é preciso "deixar emergir as dificuldades e trabalhar a partir delas, incitando os alunos à reflexão." Também visando a uma mudança na formação dos professores de PLM, Oliveira (2003) indica a necessidade de uma organização dos currículos dos cursos de formação com base em uma concepção de linguagem como prática social.

Esse objetivo de instauração de uma prática pedagógica que não se caracterize pela inércia e passividade é defendido de forma expressiva quando os alunos se posicionam durante as entrevistas. Porém, na prática cotidiana do curso, eles oscilavam em relação a esses objetivos durante os dois anos em que foram sujeitos da pesquisa que desenvolvemos. Por exemplo, embora Gabriel reconheça a necessidade de um professor ser ativo, ele não buscou alternativas para algumas de suas dificuldades. De acordo com a representação de professor que ele defende e da posição que assume sobre o processo de reescrita ("a gente via lá fragmentos do seu texto e vendo colegas fazendo observações, e era interessante porque a turma participava fazendo observações, tirando ali, colocando ali, transformando o seu texto com você."), esperávamos então que se sentisse desafiado a "pesquisar", a "estudar," como ele afirma em entrevista. Contudo, em alguns momentos, ele não reescrevia, mas respondia da forma mais fácil, própria de quem não "quer ir à luta": apagava toda a parte do texto. Apagar, sem dúvida, é uma
${ }^{18}$ Essa é a primeira das habilidades e competências indicadas nas Diretrizes Curriculares Nacionais para os cursos de Letras, p. 24. 
forma de resposta e, dependendo da situação, pode ser a expressão de uma posição ativa e tática. Porém, uma análise do processo de produção de textos de Gabriel permite-nos afirmar que, de um modo geral, essa sua posição expressou passividade. Desse modo, nesses momentos da prática, ele respondeu afirmativamente à proposta oferecida pela universidade para a sua formação.

Bianca, Helena e Heloísa também afirmam a proposta de passividade e repetição da universidade para sua formação corno professoras naqueles momentos em que não reescrevem o texto, não questionam as intervenções em seus textos ou não pesquisam para propor alternativas sobre as questões indicadas pela professora, pelos colegas da turma, ou por elas durante as discussões das aulas. Mesmo que tenham concorrido para isso fatores como a incompreensão das observações da professora, falta de tempo para reescrever e pesquisar, insegurança para realizar as alterações necessárias, entre outras, uma posição ativa exigiria uma resposta que, nas relações dialógicas estabelecidas com a professora e os colegas, poderiam ser de discordância, de refutação ou de concordância, desde que, de algum modo, fosse expressa uma contra palavra. Entretanto, também há expressões de atitudes ativas e táticas no decorrer dos anos letivos. Ainda que esses momentos sejam pouco freqüentes, são relevantes em meio às diferentes coerções e aprisionamentos a que são submetidos em sua formação. A possibilidade de eles acenarem para a subversão, a indisciplina, mesmo que ainda predominantemente no plano teórico, já nos parece um começo para a tentativa de percursos em outras trilhas, no caminho da formação de professores de PLM. Talvez, no decorrer dessas trilhas, atuando, efetivamente, como professores de PLM, Bianca, Gabriel, Helena e Heloísa possam efetivar (ou não) a proposta de De Certeau (2002, p.79) de encontrar mil maneiras de jogar/desfazer o jogo do outro e, desembaraçando-se das redes de forças e de representações estabelecidas durante a formação em Letras, possam encontrar, de forma sutil e perspicaz, maneiras de subverter a ordem. 


\section{Referências}

BAKHTIN, M. Marxismo e filosofia da linguagem. 6" ed. Traduzido por Michel Lahud e Yara F. Vieira. São Paulo: Hucitec, 1992.

BAKHTIN, M. Estética da criação verbal. 2. ed.Traduzido por Maria Ermantina G. G. Pereira. São Paulo: Martins Fontes, 1997.

BARIAN, Edna Maria. Alguns aspectos da elaboração de textos por estudantes universitários. São Paulo: PUC, 1978. Dissertação (Mestrado em Lingüística Aplicada), Pontifícia Universidade Católica de São Paulo.

BENITES, Sônia A. L. O professor de português e seu discurso. In: LEFFA, Vilson J. (org.). A interaçâo na aprendizagem das línguas. Pelotas: Educat, 2003, p. 7-26.

CAVALCANTI, M. \& MOITA LOPES, L. P. Implementação da pesquisa na sala de aula de línguas no contexto brasileiro. Trabalhos em Lingüística Aplicada, Campinas, n.17, p.133144, jan./jun. 1991.

DE CERTEAU, Michel. A invenção do cotidiano: artes de fazer. 7a ed. Traduzido por Ephraim Ferreira Alves. Petrópolis: Vozes, 2002.

DE CERTEAU, Michel. A cultura no plural. $4^{\text {a }}$ ed. Traduzido por Enid Abreu Dobránszky. Campinas: Papirus, 2005.

CONCEIÇÃO, Ruth Izabel S. O ensino de produção textual e a (re)construção da competência discursiva do aluno. Trabalhos de Lingüística Aplicada, Campinas, n. 40, p. 45-61, jul.-dez. 2002.

GARCIA, Regina L. \& ALVES, Nilda. Conversa sobre pesquisa. In: ESTEBAN, Maria Tereza \& ZACCUR, Edwiges (orgs.). Professora-pesquisadora: uma práxis em construção. Rio de Janeiro: DP \& A, 2002, p. 105-125.

GERALDI, João W. Portos de Passagem. 4. ed. São Paulo: Martins Fontes, 1997. 
KLEIMAN, Ângela (org.). A formação do professor:

perspectivas da Lingüística Aplicada. Campinas (SP): Mercado de Letras, 2001.

LIMA, Regina Célia C. Paschoal. Concepções de escrita nos PCNs de Língua Portuguesa em um curso de formação de professores. Trabalhos de Lingüística Aplicada, Campinas, n. 41, p. 51-64, jan.-jun.,2003.

MORIN, Edgard. Ciência com consciência. 4a ed. Rio de Janeiro: Bertrand Brasil, 2000.

OLIVEIRA, Maria Bernadete F. de. Revisitando a formação de professores de Língua Materna: teoria, prática e construção de identidades. Linguagem em (Dis)curso, Tubarão, v.6, n. 1, p.101-117, jan.-abr. 2006.

OLIVEIRA, Maria Bernadete F. de. Sala de aula de língua e práticas cidadãs. Trabalhos de Lingüística Aplicada, Campinas, n.41, p. 65-74, jan.-jun.2003.

OLIVEIRA, Maria Bernadete F. de. O ensino da produção textual: o saber e o fazer das professoras. In: PASSEGI, Luis \& OLIVEIRA, Maria do Socorro (orgs.). Lingüística e educação gramática, discurso, ensino. São Paulo: Terceira Margem, 2001a.

OLIVEIRA, Maria Bernadete F. de. Os discursos da escola e a construção de processos identitários de professoras de Língua Materna. Trabalhos de Lingüística Aplicada, Campinas, n.38, p. 19-28, jul.-dez.2001b.

PÉCORA, Alcir. Problemas de redação. 4a ed. São Paulo: Martins Fontes, 1992.

SANTOS, Lúcia de Fátima. Produçẫo de textos na universidade: em busca de atitudes ativas e táticas. Maceió: UFAL, 2007. Tese (Doutorado em Lingüística), Faculdade de Letras, Universidade Federal de Alagoas.

SANTOS, Lúcia de Fátima. Cultura e ensino de línguas nas Diretrizes Curriculares Nacionais de Letras. Leitura, Maceió, n.31, p. 83-97, jan.jun. 2005. 
SOARES. Magda. Que professor de Português queremos formar? In: Boletim da ABRALIN, Fortaleza, v.25, p. 211-218, 2000.

ZEICHNER, Kenneth. Formando professores reflexivos para uma educação centrada no aprendiz: possibilidades e contradições. In: ESTEBAN, Maria Tereza \& ZACCUR, Edwiges (orgs.). Professora-pesquisadora: uma práxis em construção. Rio de Janeiro: DP \& A, 2002, p. 25-54.

ZEICHNER, Kenneth. Para além da divisão entre professorpesquisador e pesquisador acadêmico. In: GERALDI, Corinta; FIORENTINI, Dário; PEREIRA, Elisabete Monteiro de A. (orgs.). Cartografias do trabalho docente: professor(a)pesquisador(a). Campinas (SP): Mercado de Letras, 1998, p. 207-236.

ZOZZOLI, Rita Maria D. Leitura e produção de textos: interrelação teoria e prática. Leia escola, Campina Grande, v.6, n.especial, p. 125-138, 2006.

ZOZZOLI, Rita Maria D. Atividades de reflexão gramatical na sala de aula e autonomia relativa do sujeito. In: LEFFA, Vilson (org.). A interação na aprendizagem de línguas. Pelotas, EDUCAT, 2003, p. 27-46.

ZOZZOLI, Rita Maria D. O processo de constituição de uma gramática do aluno leitor e produtor de textos: a busca da autonomia. Trabalhos em Lingüística Aplicada, Campinas (SP), n. 33, p. 7-21, jan.-jun., 1999. 